\title{
Post COVID-19 pneumo-hematocele: clinical presentation and treatment pathway
}

\author{
Karla Verónica Chávez ${ }^{1}$ (D) Adriana Simoneta Pimienta-lbarra ${ }^{2} \cdot$ Horacio Máruquez-González $^{3}$. \\ Juan Carlos Flores-Garcés ${ }^{4} \cdot$ Erica Sagrario Peña-Mirabal $^{5}$ · Francina Valezka Bolaños-Morales ${ }^{2}$
}

Received: 17 November 2021 / Accepted: 5 January 2022 / Published online: 18 January 2022

(c) The Author(s), under exclusive licence to The Japanese Association for Thoracic Surgery 2022

\begin{abstract}
Objectives The appearance of characteristic pulmonary lesions has been noted after COVID-19, being described as postCOVID-19 pneumo-hematocele. The aim of this study is to describe the clinical, histopathologic, and imaging features of pneumo-hematocele and to suggest a treatment algorithm for these patients.

Methods A retrospective study was performed in patients admitted with a diagnosis of SARS-CoV2 infection from March 2020 to September 2021 who presented a pneumo-hematocele on imaging studies. Clinical and demographic variables were recorded, and CT scans were analyzed. A secondary analysis was performed to estimate the risk provided by the pneumohematocele diameter of developing pneumothorax.

Results 37 patients were diagnosed with pneumo-hematoceles, $97.3 \%$ were males with a median age of $41 \pm 13$ years and $51 \%$ were smokers. The mean diameter of the pneumatocele was $6.3 \pm 2.8 \mathrm{~cm}$; they were more common on the subpleural surface and in the inferior lobe. Thirty patients had ruptured pneumo-hematoceles and developed pneumothorax (81.1\%); a total of 26 patients required surgery (70.3\%). Lesions measuring $5 \mathrm{~cm}$ had a high risk of rupture (OR 6.8, CI 95\% 1.1-42); those measuring $3 \mathrm{~cm}$ were prone to this complication. For each centimeter that the pneumo-hematocele diameter increases, the OR for rupture increases 1.5.

Conclusions It appears that post-COVID-19 pneumo-hematocele occurs secondary to encapsulation of blood accumulation inside the lung, as a result of micro-capillary bleeding, with partial reabsorption of blood and subsequent air filling. We recommend surgery for patients with pneumo-hematoceles of $5 \mathrm{~cm}$ and those with persistent lesions of $3 \mathrm{~cm}$.
\end{abstract}

Trial registration Clinical Trial Registration: NCT05067881.

Keywords SARS CoV-2 $\cdot$ COVID-19 $\cdot$ Pneumatocele $\cdot$ Pneumo-hematocele $\cdot$ Bullae

Francina Valezka Bolaños-Morales

valezka1976@gmail.com

1 Surgery Department, Hospital General Ajusco Medio, Mexico City, Mexico

2 Thoracic Surgery, Instituto Nacional de Enfermedades Respiratorias, Mexico City, Mexico

3 Congenital Heart Diseases Department, Cardiology Hospital, Centro Médico Siglo XXI, Mexico City, Mexico

4 Radiology Department, Hospital General Ajusco Medio, Mexico City, Mexico

5 Respiratory Pathology, Instituto Nacional de Enfermedades Respiratorias, Calzada de Tlalpan 4502, Sección 16, Tlalpan, 14080 Mexico City, ZP, Mexico

\section{Introduction}

As the COVID-19 pandemic has continued worldwide during 2020 and 2021, an increasing number of long-term complications are emerging, such as cardiac affection [1, $2]$, neurologic disorders [3, 4], and pulmonary fibrosis [5, 6]. Recently, the appearance of characteristic pulmonary lesions has been noted, being described as "giant bulla" [7-9] or post-COVID-19 pneumatocele [10, 11].

A pneumatocele is described as an air-filled pseudocyst, with a thin wall that forms in the lung interstitium [12], it can be filled with liquid or present with air-fluid levels; when it has blood, it is called pneumo-hematocele and may occur secondary to bleeding into the cyst posterior to trauma [13]. Generally, pneumatoceles are present in one of the two settings: infectious or post-traumatic events, including 
mechanical ventilation, surgery, and diffuse interstitial pulmonary emphysema. In $85 \%$ of the cases, patients are 30 years old or younger [14]. In both cases, a tissue disruption occurs, which can be filled with pleural fluid, blood, or air, until a balance of lung pressures is reached between the cavities in the surrounding tissue $[15,16]$. After infectious pneumonia, the inflammatory and airway secretions may form a bronchial valve, which allows the air to enter but not to come out, subsequently forming a cyst [12]. The most common infectious agents associated with pneumatocele formation are bacteria (Streptococcus pneumoniae [17], Staphylococcus aureus [18]), but they can also present in fungal infections (Pneumocystis jiroveccii [19]), mycobacteria, and some adenoviruses.

Most of the publications on post-COVID-19 pneumohematoceles are case reports which have described the clinical and imaging presentation [20-22] of these patients without further discussion on the etiology and treatment. Hence, the aim of this study is to describe the clinical, histopathologic, and imaging features of post-COVID-19 pneumo-hematoceles (PHC) and secondarily, to suggest a treatment algorithm in these patients.

\section{Subjects and methods}

From March 2020 to September 2021, a retrospective study was performed in patients admitted with a diagnosis of SARS-CoV2 infection in two hospitals in Mexico City. The inclusion criteria were adults with a positive protein chain reaction for SARS-CoV2, who presented PHC on imaging studies. Exclusion criteria were loss of follow-up or incomplete clinical records.

Clinical and demographic variables were recorded, including comorbidities, smoking history, laboratory results, D-Dimer (DD), reactive C-protein (RCP), infection history, and surgical records. Their thoracic computed tomography scans (General Electric Brightspeed Elite 16 high-resolution CT scanner) were evaluated and classified according to the following characteristics of the PHC: (1) single or multiple lesions, (2) laterality in one or both hemithorax, (3) localization in the lung (categorized as central "peribronchovascular" or peripheral "subpleural"), (4) diameter of the predominant lesion, (5) content, and (6) affected lobule. All patients signed a consent upon hospitalization and before surgery. The study was approved by the Hospitals Ethics and Research Department.

\section{Surgical procedure}

Patients who underwent surgery were intubated with selective bronchial intubation. If there were previous chest tube orifices, they were used to place the ports for video-assisted thoracoscopic surgery (VATS); if an open thoracotomy was planned, a standard posterolateral incision was performed.

Once the lesion is identified, it is opened and a complete drainage of the hematic material is performed; the resulting pouch is then excised at the base with surgical staples. A 24-32 French drainage is placed to ensure outflow of possible air leaks, connected to a water seal with intermittent suction. Once a complete pulmonary expansion is achieved and no air leaks are identified, the tube is removed, and the patient is discharged.

\section{Statistical analysis}

Data were expressed as median \pm standard deviation (SD) with range values whenever a normal distribution was observed. Non-parametric descriptive measures were used whenever a variable distribution was not Gaussian. A secondary analysis was used to estimate the risk of pneumothorax by PHC diameter; a ROC curve analysis was determined, and the OR was calculated with diameters of $3 \mathrm{~cm}$ and $5 \mathrm{~cm}$ adjusted for smoking (Mantel-Haenszel test). To estimate the risk provided by the increase in the diameter of the lesion, a logistic regression analysis was performed and the crude value was reported. Microsoft Excel for Mac 12.2.6 and IBM® SPSS ${ }^{\circledR}$ Statistics version 22.0 (IBM Inc. Chicago, IL) were employed for the statistical analysis.

\section{Results}

A total of 37 patients were diagnosed with PHC during the study, almost all of them were male (97.3\%) with an age of $41 \pm 13$ years old. More than half of these patients (54.1\%) presented PHC outside the hospital and were admitted to the emergency room, the rest were diagnosed during hospitalization due to COVID-19; a total of 12 patients (32.4\%) had a previous history of mechanical ventilation. The median days from SARS CoV-2 infection and the diagnosis of PHC were $23 \pm 11$ days. Thirty patients had PHC rupture and developed pneumothorax $(81.1 \%)$. More than half of the patients were active smokers $(51.8 \%)$, the rest of the clinical and demographic variables are listed in Table 1.

A total of 26 patients underwent surgery (70.3\%), which was more frequently by VATS $(76 \%)$ (Table 2$)$. There were no serious immediate postoperative complications, only one post-thoracotomy patient had a superficial wound infection. During follow-up, the hospital stay was $20 \pm 24$ days and five patients died (14.3\%) from other COVID-19 complications (Fig. 1).

When determining the size from which patients presented PHC rupture and pneumothorax, the ROC curve had an AUC of $0.73(0.54-0.92)$, defining $3 \mathrm{~cm}$ as the earliest predictor (Fig. 2). The logistic regression analysis showed that patients with lesions measuring $5 \mathrm{~cm}$ had the higher risk for rupture 
Table 1 Clinical and demographic variables of patients with PHC

\begin{tabular}{|c|c|c|c|}
\hline \multicolumn{2}{|l|}{ Qualitative variables } & $N(37)$ & $\%$ \\
\hline \multicolumn{4}{|l|}{ Gender } \\
\hline \multicolumn{2}{|l|}{ Female } & 1 & 2.70 \\
\hline \multicolumn{2}{|l|}{ Male } & 36 & 97.30 \\
\hline \multicolumn{4}{|l|}{ Comorbidities } \\
\hline \multicolumn{2}{|l|}{ Diabetes Mellitus 2} & 6 & 17.10 \\
\hline \multicolumn{2}{|l|}{ Systemic hypertension } & 4 & 11.80 \\
\hline \multicolumn{2}{|l|}{ Smoking } & 18 & 51.40 \\
\hline \multicolumn{2}{|l|}{ Inhaled drugs } & 2 & 5.40 \\
\hline \multicolumn{2}{|l|}{ HIV infection } & 1 & 2.7 \\
\hline \multicolumn{2}{|l|}{ Alcoholism } & 5 & 13.50 \\
\hline \multicolumn{2}{|l|}{ Pulmonary Tuberculosis } & 1 & 2.70 \\
\hline \multicolumn{2}{|l|}{ History of Mechanical Ventilation } & 12 & 32.4 \\
\hline \multicolumn{4}{|l|}{ Clinical presentation } \\
\hline \multicolumn{2}{|l|}{ Outpatient } & 20 & 54.1 \\
\hline \multicolumn{2}{|l|}{ Inpatient } & 17 & 45.9 \\
\hline Quantitative variables & Median & Percentile 25 & Percentile 75 \\
\hline Age (years) & 42 & 32 & 53 \\
\hline $\mathrm{DD}^{*}(\mathrm{ng} / \mathrm{mL})$ & 2305 & 1180 & 4070 \\
\hline $\mathrm{RCP}(\mathrm{mg} / \mathrm{L})$ & 17 & 6.76 & 30 \\
\hline Hospital stay (days) & 20 & 11 & 33 \\
\hline Days between COVID-19 and PHC & 23 & 14 & 30 \\
\hline
\end{tabular}

$D D$ D-dimer, $R C P$ reactive-C protein, $P H C$ pneumo-hematocele

*Normal range $0-500 \mathrm{ng} / \mathrm{mL}$

Table 2 Treatment in symptomatic PHC patients

\begin{tabular}{llr}
\hline Intervention & $N(37)$ & $\%$ \\
\hline None & 4 & 10.8 \\
Chest tube & 4 & 10.8 \\
Bilateral Chest tube & 1 & 2.7 \\
Pulmonary resection & & \\
VATS* & 19 & 51.6 \\
Thoracotomy & 6 & 16.1 \\
Drainage and decortication & 1 & 2.7 \\
Chemical pleurodesis & 1 & 2.7 \\
Total & 37 & 100.0 \\
\hline
\end{tabular}

*VATS: Video-assisted thoracoscopic surgery

(OR 6.8, CI 95\% 1.1-42), whereas those with PHC measuring $3 \mathrm{~cm}$ were prone to present this complication (OR 4.8, CI 95\% 2-5.6). For each centimeter that the PHC diameter increases, the OR for rupture increases 1.5 (Fig. 3).

\section{Radiology}

In all patients, PHC were described as well delimited complex air spaces with a thin, $2 \mathrm{~mm}$ wall and heterogeneous content at the expense of a hyperdense level that precipitates with attenuation coefficients ranging between 12 and 16 Hounsfield Units (Fig. 4). The most common form of presentation was patients with multiple and unilateral lesions; the mean diameter of the PHC was $6.3 \pm 2.8 \mathrm{~cm}(1.0-12.3 \mathrm{~cm})$ and appeared most frequently in the periphery of the lung (78.4\%), being the inferior lobe the most commonly affected area in $54.1 \%$ of the cases (Table 3 ).

\section{Histologic results}

The pathological specimens macroscopically showed a large accumulation of blood between the collapsed and rejected lung parenchyma. The pleural surface was thin and preserved, with the pulmonary parenchyma enclosing the hematic material forming a capsule (Fig. 5).

The histological analysis showed edema in the subpleural space, with mononuclear infiltration, reactive mesothelial cells, and vascular proliferation over the hematic material (Fig. 6A, B). The lung parenchyma was displaced and had fibroconnective tissue surrounding the hematic material; hemosiderophages were also found, possibly secondary to old bleeding and mononuclear inflammatory infiltration (Fig. 6C). Peripheral to the lung lesion, a thick arterial wall 


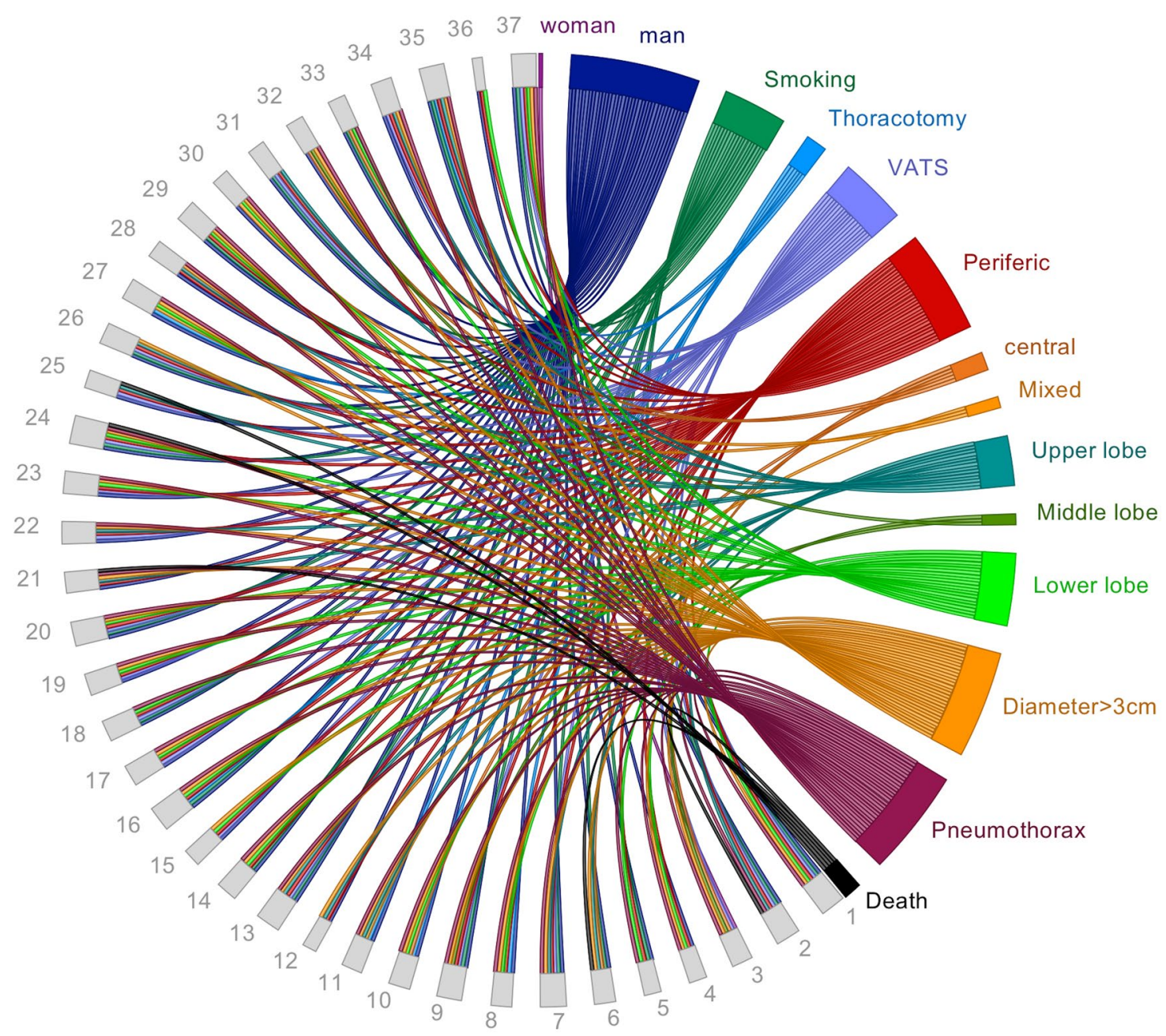

Fig. 1 String graphic of patients with PHC

with important vasculitis was observed with inflammatory obstruction of the vascular lumen (Fig. 6D).

\section{Discussion}

As the COVID-19 pandemic continues, we are identifying new medium and long-term complications following SARSCoV2 infection, with PHC being a new entity identified in these patients. The appearance of these lesions has become increasingly frequent, they occur in relatively younger patients and generally in those with the moderate and severe disease around day 20 after diagnosis. In our study, more than half of the patients were active smokers, which has been previously related to the formation of blebs and spontaneous pneumothorax in non-COVID-19 patients [23].

Pneumo-hematoceles present in one of the two forms: (1) with symptoms due to pneumothorax, lung displacement, and rupture or (2) as asymptomatic PHC in imaging studies.
Depending on the PHC size and the hemodynamic stability of the patient, surgery is carried out, preferably with VATS as described later.

According to the clinical and epidemiological context of the patients, based on the 2008 Fleischner Society Glossary of Terms for Thoracic Imaging and having appeared de novo, the complex cystic spaces presented in the study can be categorized as pneumatoceles [24]. Some authors reported similar findings in a patient with COVID-19 and described the airspace as a bulla rather than a pneumatocele [25]. Radiologically, it may be difficult to differentiate between the two conditions, but pathologically, each entity has different features: bullae are the result of the destruction of the alveoli, resulting in airspace with a fibrous wall and possible intracystic trabeculae, whereas the post-COVID-19 PHC are secondary to the encapsulation of blood accumulation.

A retrospective analysis of $\mathrm{CT}$ findings in patients with COVID-19 from China by Wu et al. reported the presence of pneumatoceles in only two cases [26]. Most of the lesions 


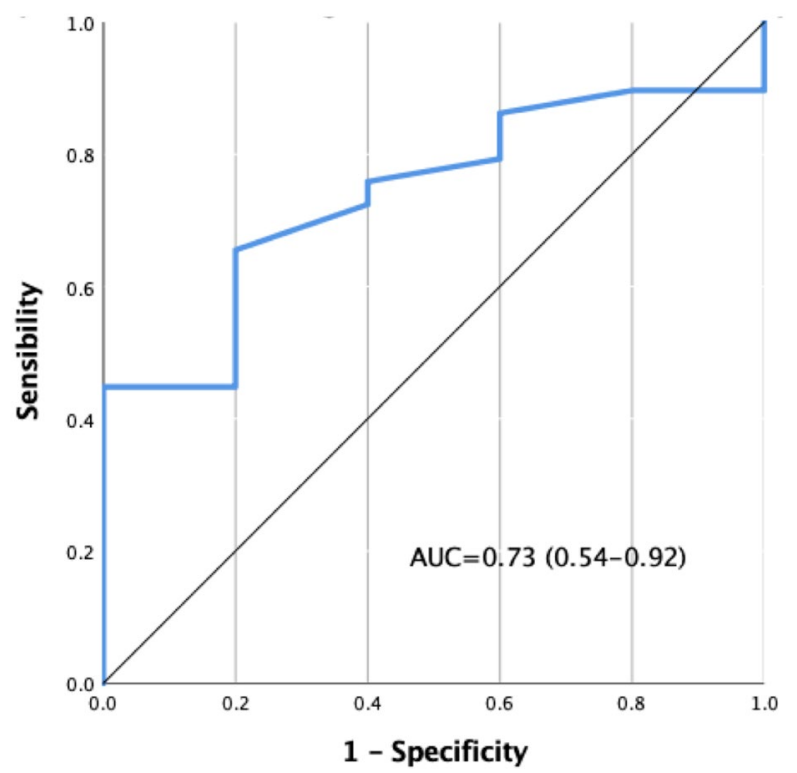

Fig. 2 ROC curve for PHC diameter and pneumothorax

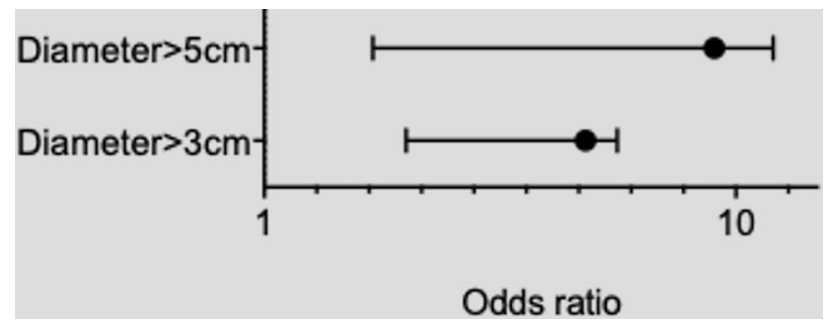

Fig. 3 OR for developing pneumothorax according to PHC size found in our study were peripherally localized; we assume that this finding may be a reflection of the COVID-19 predilection to affect the subpleural space as demonstrated in previous imaging and pathologic studies [27].

Regarding histological evaluation, Hamad et al. reported a thin tissue wall demarcating lesions similar to PHC, with marked fibroblast proliferation, lymphocyte infiltration, intra-alveolar hemorrhage, and pneumocyte proliferation [11]. According to our findings, the histological changes were similar when the lesion was close to the pleura, but in intrapulmonary cases, the connective tissue surrounding the hematic material showed a reactive inflammatory process secondary to a foreign body, very different from the previous descriptions of COVID-19 lung affection as diffuse alveolar damage, organizing pneumonia, reactive type II pneumocytes, and chronic interstitial pneumonia [28]. In another report by Barnes et al., a small vessel injury with features of acute capillaritis in association with neutrophilic infiltration into the alveolar space and tracheal mucosa was described, which is consistent with our findings of vasculitis and inflammatory vascular occlusion [29].

With these findings, we consider that the term "pulmonary hematocele" or "pneumo-hematocele" is more proper than pneumatocele, due to the fact that the primary lesion appears to be a hematic accumulation due to micro-capillary inflammatory bleeding with a secondary inflammatory fibrotic process enclosed by the lung parenchyma, with subsequent total or partial reabsorption of the blood. The remaining lesion, which can appear as a giant bulla, is the "capsule" of this inflammatory process, which can easily present rupture of its thin wall, causing pneumothorax [30].
Fig. 4 Lung window chest tomography of patients with COVID-19 and PHC. A Patient with two PHC at the level of both upper segments of the lower lobes; note the right pneumothorax and lung parenchyma with multisegmental areas of alveolar occupation. B Patient with a PHC at the level of the middle lobe and in the left anterior basal segment, the right one with a subtle liquid level. $\mathbf{C}$ Patient with severe COVID-19, D the same patient one month apart, with a typical PHC on the left lung

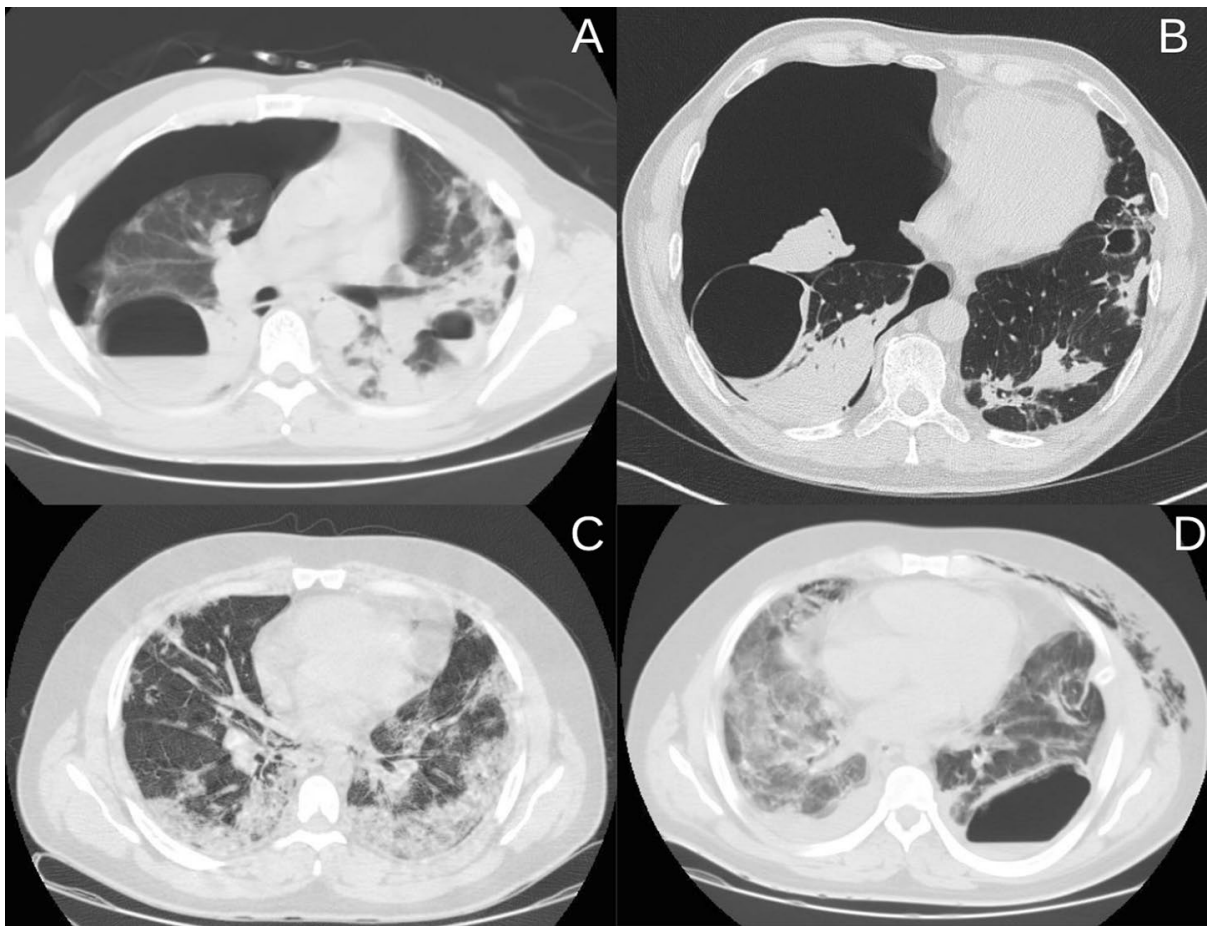


Table 3 Pneumo-hematoceles radiographic findings

\begin{tabular}{llr}
\hline & $N(37)$ & $\%$ \\
\hline PHC localization & & \\
Peripheric & 29 & 78.4 \\
Central & 5 & 13.5 \\
Mixed & 3 & 8.1 \\
Number of PHC & & \\
Single & 13 & 35.1 \\
Multiple & 24 & 64.9 \\
PHC lateralization & & \\
Unilateral & 27 & 73.0 \\
Bilateral & 10 & 27.0 \\
Affected lobe & & \\
Superior & 14 & 37.8 \\
Middle & 3 & 54.1 \\
Inferior & 20 & \\
\hline
\end{tabular}

\section{Proposed treatment pathway}

To treat these patients, a multidisciplinary team was formed by clinicians, general and thoracic surgeons, radiologists, and pathologists; together, the most adequate treatment pathway to standardize the management of PHC to improve the patient's outcome was discussed due to the lack of consensus and guidelines to treat this COVID-19 complication (Fig. 7).

According to the experience of the past 18 months, a treatment pathway was proposed in patients with confirmed SARS-CoV2 infection in the two clinical scenarios:

(1) Symptomatic or ruptured PHC: the patient is admitted to the hospital and a thoracic X-Ray is performed. If the pneumothorax found is larger than $20 \%$ or has more than $2 \mathrm{~cm}$ of separation between the pleurae, a chest tube or a minimally invasive drainage system with a negative pressure system is placed; a chest CT scan is then performed to rule out PHC.

(2) Asymptomatic or non-ruptured PHC: if the patient presents dyspnea or chest pain during outpatient or inpatient follow-up, a simple thoracic CT scan is performed.

Once the PHC is diagnosed in the thorax tomography, we measure its larger diameter, assess if the lesion is single or multiple, and its laterality. If the lesion is wider than $5 \mathrm{~cm}$, surgery should be considered depending on the hemodynamic status of the patient: if stable, the surgery is carried out; if the patient is hemodynamically unstable or unfit for surgery, a percutaneous catheter drainage or a chest tube is placed and aggressive antibiotic management is initiated until their clinical condition improves to perform the pulmonary resection.

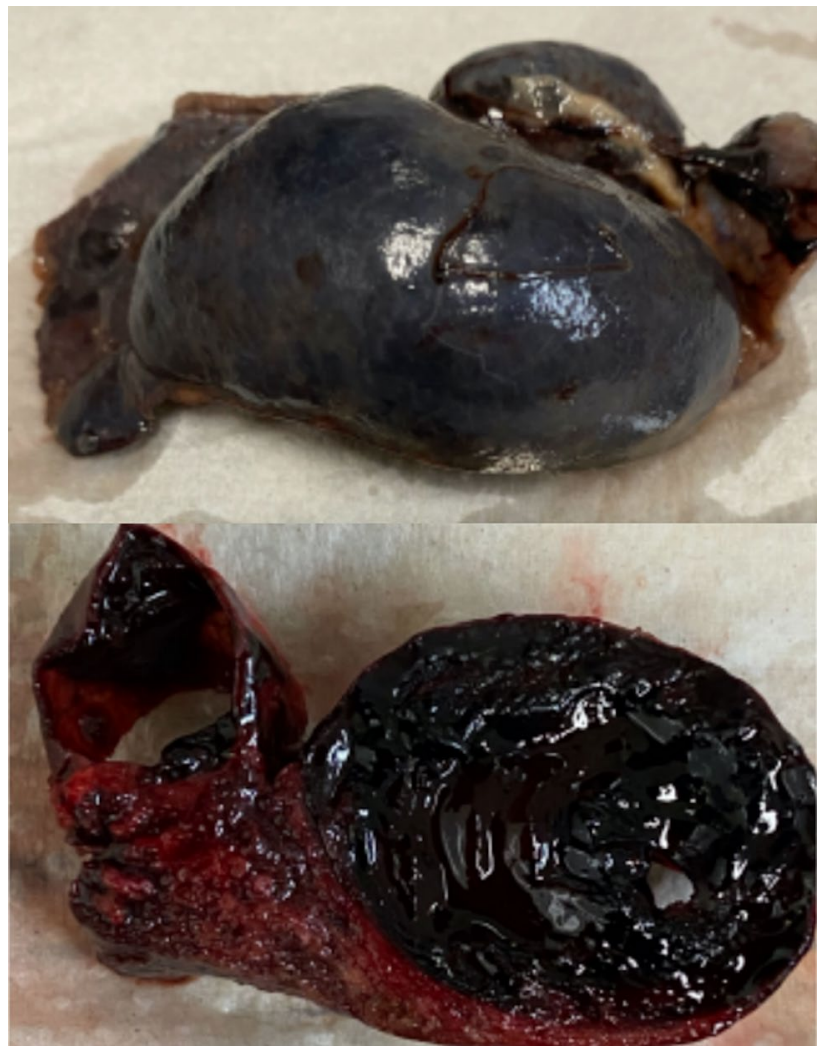

Fig. 5 Macroscopic appearance of a pulmonary resection with a PHC

If the pulmonary lesion measures less than $5 \mathrm{~cm}$ and does not cause any symptoms, conservative management is recommended and the patient is monitored with thoracic CT in 4 weeks. If the PHC persists larger than $3 \mathrm{~cm}$, resection should be performed due to the high risk of bleeding, infection, or rupture.

\section{Conclusions}

This manuscript describes a new entity described as pneumo-hematocele with clinical, imaging, histologic, and surgical findings. According to the experience obtained, a treatment algorithm is proposed to standardize the management in these patients, suggesting surgical resection of PHC measuring $5 \mathrm{~cm}$ or larger, as well those asymptomatic patients with persistent lesions above $3 \mathrm{~cm}$.

Because of the previously described characteristics of PHC, we consider it a different entity from other bullous diseases of the lung, thus, it should be treated differently. The rise in the incidence of these lesions may be due to the increase in the survival of patients with new therapies and the advance of knowledge about COVID-19, as well as the progress in vaccination throughout the world; we do not rule out that the new strains of this virus are more prone to cause 
Fig. 6 Histologic features of a Pneumo-hematocele. A Edema in the subpleural space, with mononuclear infiltration, reactive mesothelial cells. B Vascular proliferation over the hematic material. C Displacement of lung parenchyma with fibroconnective tissue surrounding the hematic material and hemosiderophages. D Small artery with vasculitis and inflammatory obstruction of the vascular lumen

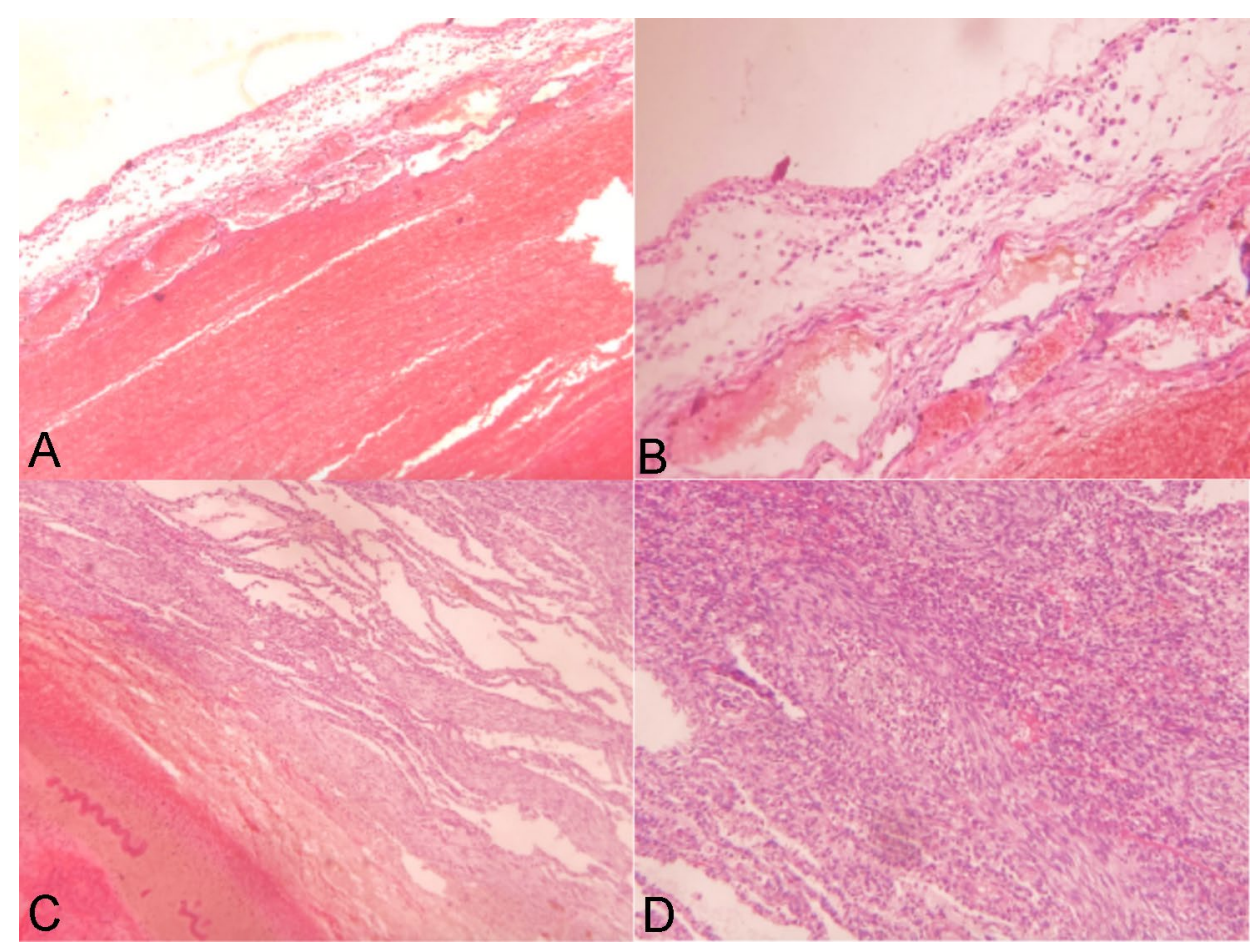

these and other complications compared to the wild-type SARS-CoV2.

Although this manuscript reports the highest number of PHC cases to date, no prospective studies or guidelines are yet available, so the recognition of these cases and their further analysis still is of utmost importance to continue to elucidate the behavior of COVID-19. 
Fig. 7 Treatment algorithm for patients with PHC

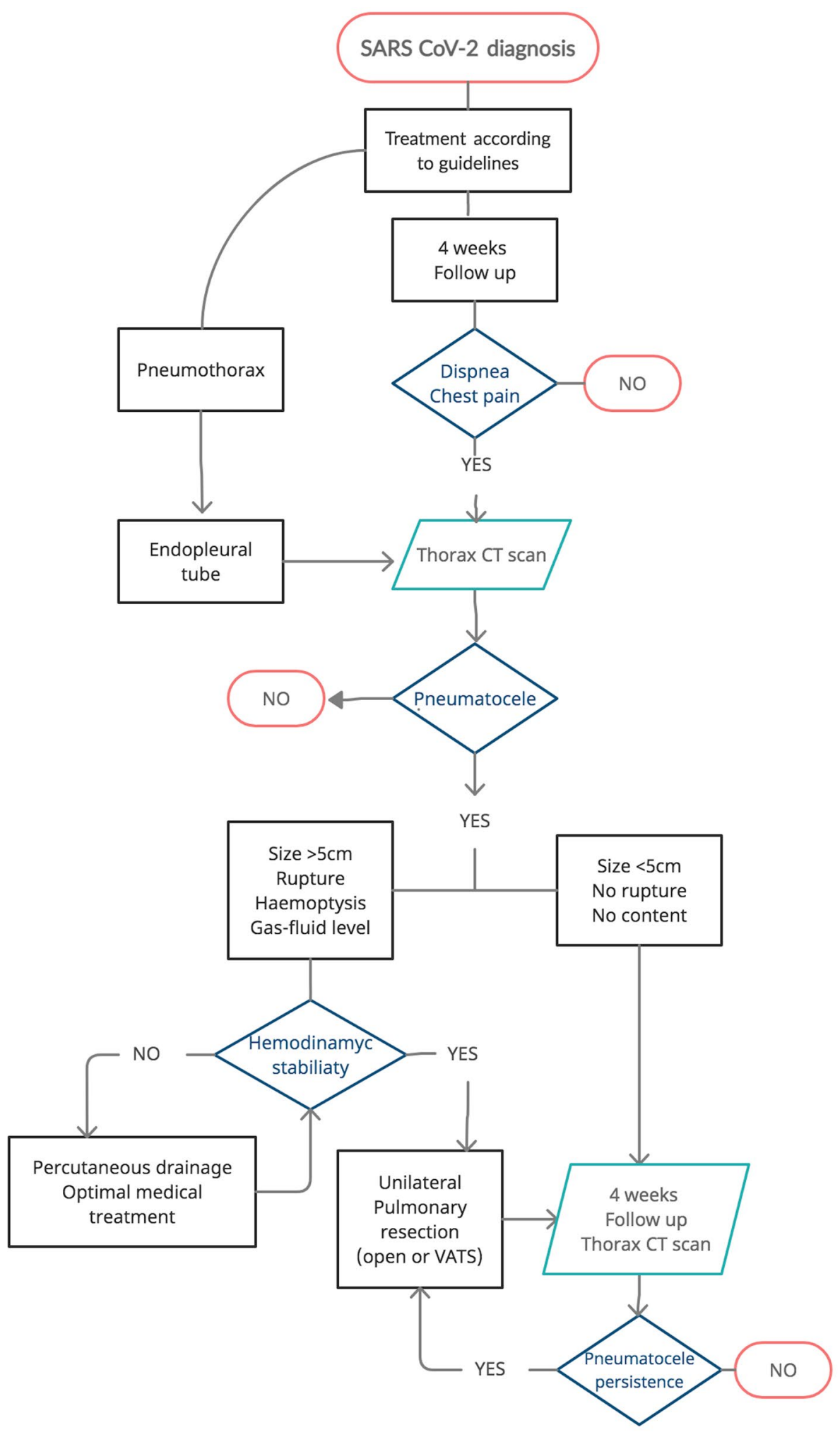


Funding No funding or grant was given to this manuscript.

\section{Declarations}

Conflict of interest The authors disclaim they do not have any conflict of interest.

\section{References}

1. Ho JSY, Sia CH, Chan MYY, Lin W, Wong RCC. Coronavirusinduced myocarditis: a meta-summary of cases. Heart Lung. 2020;49:681-5. https://doi.org/10.1016/J.HRTLNG.2020.08.013.

2. Inciardi RM, Lupi L, Zaccone G, Italia L, Raffo M, Tomasoni D, Cani DS, Cerini M, Farina D, Gavazzi E, Maroldi R. Cardiac involvement in a patient with coronavirus disease 2019 (COVID19). JAMA Cardiol. 2020;5(7):819-24. https://doi.org/10.1001/ JAMACARDIO.2020.1096.

3. Chen X, Laurent S, Onur OA, Kleineberg NN, Fink GR, Schweitzer F, Warnke C. A systematic review of neurological symptoms and complications of COVID-19. J Neurol. 2021;268(2):392402. https://doi.org/10.1007/S00415-020-10067-3.

4. Maury A, Lyoubi A, Peiffer-Smadja N, de Broucker T, Meppiel E. Neurological manifestations associated with SARS-CoV-2 and other coronaviruses: a narrative review for clinicians. Rev Neurol. 2021;177(1-2):51-64. https://doi.org/10.1016/J.NEUROL.2020. 10.001 .

5. Ojo AS, Balogun SA, Williams OT, Ojo OS. Pulmonary fibrosis in COVID-19 survivors: predictive factors and risk reduction strategies. Pulm med. 2020. https://doi.org/10.1155/2020/6175964.

6. Gentile F, Aimo A, Forfori F, Catapano G, Clemente A, Cademartiri F, Emdin M, Giannoni A. COVID-19 and risk of pulmonary fibrosis: the importance of planning ahead. Eur j prev cardiol. 2020;27(13):1442-6. https://doi.org/10.1177/2047487320932695.

7. Sun R, Liu H, Wang X. Mediastinal emphysema, giant bulla, and pneumothorax developed during the course of COVID-19 pneumonia. Korean J Radiol. 2020;21:541-4. https://doi.org/10.3348/ kjr.2020.0180.

8. Sato L, Kinoshita N, Nakamoto T, Ohmagari N. Hemoptysis and a newly formed lung bulla in a case of convalescent COVID-19 pneumonia. Intern Med. 2021;60:803-5. https://doi.org/10.2169/ internalmedicine.5684-20.

9. Xu W, Luo X, Wang H, Shen C, Song Y, Sun T, et al. Pulmonary emphysema, bullae, and pneumothorax in COVID-19 pneumonia. Radiol Case Reports. 2021;16:995-8. https://doi.org/10.1016/j. radcr.2021.01.055

10. Sanivarapu RR, Farraj K, Sayedy N, Anjum F. Rapidly developing large pneumatocele and spontaneous pneumothorax in SARSCoV-2 infection. Respir Med Case Reports. 2020;31: 101303. https://doi.org/10.1016/j.rmcr.2020.101303.

11. Hamad A-MM, El-Saka HA. Post COVID-19 large pneumatocele: clinical and pathological perspectives. Interact Cardiovasc Thorac Surg. 2021. https://doi.org/10.1093/icvts/ivab072.

12. Jamil A, Kasi A. Pneumatocele. In: Treasure Island (FL). StatPearls Publishing; 2021.

13. Desrues B, Delaval P, Motreff C, Kernec J, Dormoy C, Pencolé $\mathrm{C}$, et al. Post-traumatic pneumatocele and hemato-pneumatocele of the lung. Apropos of 3 cases. Rev Mal Respir. 1988;5:67-70.

14. Kaira K, Ishizuka T, Yanagitani N, Sunaga N, Hisada T, Mori M. Pulmonary traumatic pneumatocele and hematoma. Jpn J Radiol. 2009;27(2):100-2. https://doi.org/10.1007/S11604-008-0296-X.
15. Al-Ghafri M, Al-Hanshi S, Al-Ismaily S. Two cases of pneumatoceles in mechanically ventilated infants. Oman Med J. 2015;30(4):299-302. https://doi.org/10.5001/OMJ.2015.59.

16. Liu K, Zeng Y, Xie P, Ye X, Xu G, Liu J, et al. COVID-19 with cystic features on computed tomography. Medicine (Baltimore). 2020;99: e20175. https://doi.org/10.1097/md.0000000000020175.

17. Purdy GD, Cullen M, Yedlin S, Bedard MP. An unusual neonatal case presentation: Streptococcus pneumoniae pneumonia with abscess and pneumatocele formation. J Perinatol. 1987;7:378-81.

18. Ishiguchi S, Nishioka K, Kanetake Y, Sugiyama K, Shibayama M. Pneumatocele accompanying staphylococcal pneumonia. Rinsho Hoshasen. 1966;11:644-53.

19. Js S, Pc G. Pulmonary cysts associated with Pneumocystis carinii pneumonia in patients with AIDS. Radiology. 1989;173:33-5. https://doi.org/10.1148/RADIOLOGY.173.1.2789413.

20. Murayama D, Kojima D, Hino A, Yamamoto Y, Doiuchi T, Horikawa A, et al. A case of bulla formation after treatment for COVID-19 pneumonia. Radiol Case Rep. 2021;16:1162-4. https://doi.org/10.1016/j.radcr.2021.03.003.

21. Brahmbhatt N, Tamimi O, Ellison H, Katta S, Youssef J, Cortes $\mathrm{C}$, et al. Pneumatocele and cysts in a patient with severe acute respiratory syndrome coronavirus 2 infection. JTCVS Tech. 2020;4:353-5. https://doi.org/10.1016/j.xjtc.2020.08.047.

22. Capleton P, Ricketts W, Lau K, Ellis S, Sheaff M, Giaslakiotis K, et al. Pneumothorax and pneumatocoele formation in a patient with COVID-19: a case report. SN Compr Clin Med. 2021;3:269_ 72. https://doi.org/10.1007/s42399-020-00689-z.

23. Bense L, Eklund G, Wiman LG. Smoking and the increased risk of contracting spontaneous pneumothorax. Chest. 1987;92:1009_ 12. https://doi.org/10.1378/CHEST.92.6.1009.

24. Hansell DM, Bankier AA, MacMahon H, McLoud TC, Muller NL, Remy J. Fleischner society: glossary of terms for thoracic imaging. Radiology. 2008;246:697-722. https://doi.org/10.1148/ RADIOL.2462070712.

25. Fan Q, Pan F, Yang L. Spontaneous pneumothorax and subpleural bullae in a patient with COVID-19: a 92-day observation. Eur J Cardio-Thoracic Surg. 2020;58:858-60. https://doi.org/10.1093/ ejcts/ezaa305.

26. J W, LC F, XY X, J Q, J Z, QX M, et al. Novel coronavirus pneumonia (COVID-19) CT distribution and sign features. Zhonghua Jie He He Hu Xi Za Zhi 2020;43:E030. https://doi.org/10.3760/ CMA.J.CN112147-20200217-00106

27. Bernheim A, Mei X, Huang M, Yang Y, Fayad ZA, Zhang N, et al. Chest CT findings in coronavirus disease-19 (COVID-19): relationship to duration of infection. Radiology. 2020;295:685-91. https://doi.org/10.1148/RADIOL.2020200463.

28. Calabrese F, Pezzuto F, Fortarezza F, Hofman P, Kern I, Panizo A, et al. Pulmonary pathology and COVID-19: lessons from autopsy. The experience of European pulmonary pathologists. Virchows Arch. 2020;477:359. https://doi.org/10.1007/ S00428-020-02886-6.

29. Barnes BJ, Adrover JM, Baxter-Stoltzfus A, Borczuk A, CoolsLartigue J, Crawford JM, et al. Targeting potential drivers of COVID-19: neutrophil extracellular traps. J Exp Med. 2020. https://doi.org/10.1084/JEM.20200652.

30. Oscar MPJ. Air leaks, pneumatoceles, and air spaces in Covid-19 pneumonia. Am J Emerg Med. 2020. https://doi.org/10.1016/j. ajem.2020.08.098.

Publisher's Note Springer Nature remains neutral with regard to jurisdictional claims in published maps and institutional affiliations. 